\title{
Labour Market Institutions and the Cyclical Dynamics of Employment*
}

\author{
Luca Nunziata ${ }^{\dagger}$ \\ Nuffield College, University of Oxford
}

This version: 19 November, 2001

\begin{abstract}
We present an empirical analysis of the effects of labour market institutions on the employment dynamics over the cycle. In the first part of the paper a theoretical framework is provided with particular emphasis on working time regulations. The conclusions of the theory are tested in the second part on a sample of 20 OECD countries observed over the period 1975-1997. The empirical analysis is focused on expansions, contractions and different expansion segments. The claims of the theory are confirmed and a measure of the influence of labour market institutions on the employment responsiveness to the business cycle is provided through simulations.
\end{abstract}

JEL classification: J23, E32, J32.

Keywords: employment protection, employment dynamics, business cycles, labour market institutions, working time regulations.

\footnotetext{
${ }^{*}$ I wish to thank Stephen Nickell for his invaluable comments and insights, David Hendry, John Muellbauer, Christopher Bliss, Stephen Bond and two anonymous referees for their very helpful remarks. The usual disclaimer applies. Financial support from the Bank of Italy is also acknowledged.

${ }^{\dagger}$ Address for correspondence is Nuffield College, New Road, Oxford, OX1 1NF, UK. Tel: +441865-278526, Fax: +44-1865-278621, Email: luca.nunziata@nuffield.ox.ac.uk.
} 


\section{Introduction}

The analysis of the impact of labour market institutions on the economic performance of OECD countries has proliferated in the empirical economic literature of recent years. Studies such as Belot and van Ours (2000), Blanchard and Wolfers (2000), Bertola et al. (2001) and Nickell et al. (2001) have principally focused on the impact of labour market institutions on the unemployment performance of OECD countries in the last decades ${ }^{1}$. One important feature of labour market institutions remains however unexplored at the empirical level: their impact on the employment dynamics over the cycle ${ }^{2}$. This paper proposes to fill this gap.

The theoretical literature that analyses the employment cyclical dynamics over the cycle has largely focused on the influence of the adjustment costs induced by the employment protection legislation ${ }^{3}$. Less attention has been devoted to the analysis of the impact of working time regulations. Indeed, most of the theoretical studies about the employment impact of working time regulations are concentrated on their static properties, with special attention to exogenous worksharing policies ${ }^{4}$. The focus of this paper is, instead, on working time regulations along the cycle.

In what follows, Section 2 introduces a simple theoretical analysis of the effects of working time regulations and employment protection on the employment dynamics over the cycle using a modified version of Nickell (1978)'s seminal model of cyclical labour demand. In Section 3 the theoretical implications of the model are tested on a sample of 20 OECD countries observed for the period 1975 - 1997. The analysis concentrates on the impact of labour market institutions on different phases of the cycle, as well as over different segments of each phase ${ }^{5}$. Some conclusive remarks are presented in Section 4.

\section{The Theoretical Framework}

\subsection{The Model}

Following Nickell's approach ${ }^{6}$, it is assumed that a representative firm faces a known deterministic cyclical weekly demand for its products $x(t)$, of period $2 \tau$. Other rele-

\footnotetext{
${ }^{1}$ Nickell and Nunziata (2000) examine instead the effect of institutions on the employment adjustment speed in a model of dynamic labour demand, while Nunziata and Staffolani (2001) concentrate on the impact on permanent and temporary employment population ratios. A useful survey on labour market institutions is provided by Nickell and Layard (1999) while some introductory readings are Layard, Nickell and Jackman (1991) and Nickell (1997).

${ }^{2}$ For example, Nickell (1997b) and Nickell and Nunziata (2000), although focusing on the effects of labour market institutions on the dynamics of employment, do not analyse them in a cyclical perspective.

${ }^{3}$ See, among the others, Nickell (1986), Bentolila and Bertola (1990) and Hamermesh (1993). An excellent survey is contained in Bertola (1998). See also Garibaldi and Mauro (1999) for an analysis of the impact of employment protection legislation on job creation.

${ }^{4}$ See for example Hart (1987), Calmfors and Hoel (1989) and Hoon (1995). An exception to this is Staffolani (1992).

${ }^{5}$ The terminology adopted in the literature about the different phases of the cycle is not exempt from confusion. To avoid any misunderstanding, in what follows our terminology will be the following: an expansion (contraction) phase is the phase during which cyclical output is growing (declining) and the rise (decrease) in output is translated into a rise (decrease) in employment; a boom (slump) is the phase when cyclical output and employment are greater (lower) than the trend.

${ }^{6}$ An alternative approach to the modelling of employment dynamics over the cycle is Bentolila and Bertola (1990). Their model has the advantage of incorporating the role of uncertainty in a stochastic setting. However, we benefit from Nickell's deterministic approach in terms of simplicity as well as in the straightforward identification of an empirical test of the implications of the theory.
} 
vant assumptions are the absence of inventories, no voluntary quits and the constancy of the level of capital over the cycle. This means that the firm's decisions about the capital stock are not affected by the deviations from trend demand growth, and labour is the only variable factor that can accommodate cyclical variations in demand. In this framework, labour supply issues are not taken into account.

Given a fixed stock of $\operatorname{desks}^{7} M$, the firm sets $M_{1}(t)$ of these going for $h(t)$ hours a week, utilizing one worker on each operating desk. Assuming a single shift system ${ }^{8}$, the employment of the firm at any point in time is $M_{1}(t)$ and the output produced is $h(t) M_{1}(t)$.

The problem for the profit maximizing firm is the following:

$$
\max \int_{0}^{\infty} e^{-r t}\left\{p h M_{1}-W(h) M_{1}-a A-d D\right\} d t
$$

subject to:

$$
\begin{gathered}
\dot{M}_{1}=A-D, \quad A \geq 0, D \geq 0 \\
M-M_{1} \geq 0 \\
x-h M_{1} \geq 0
\end{gathered}
$$

where $p$ is the output price (constant), $W(h)$ is the wage schedule, $A$ is the accessions rate, $D$ is the dismissal rate, and $a$ and $d$ are respectively the hiring and firing costs per employee.

The dynamics of employment are determined by the combined effect of accessions and dismissals in (2) while (3) states that the level of desks in operation cannot exceed the stock of desks $M$ owned by the firm. At any moment in time the output produced by the firm is demand constrained, given that inventories are ruled out, as in (4).

The wage schedule specification faced by the firm is a more general version of the one presented in the working time literature. Standard hours are assumed to be fixed by law at a level $\bar{h}_{1}$, and actual hours can be adjusted by the firm at a level that can be greater or lower than $\bar{h}_{1}$. The hours decision of firms is regulated by working time standards legislation. On a theoretical level this legislation can affect both upward as well as downward flexibility of hours i.e., respectively, the cost of overtime and the cost of setting actual hours below the standard level. There is no specific theoretical reason why upward and downward internal flexibility should be regulated in the same way, so we prefer to keep these two parameters distinct ${ }^{9}$.

With regards to upward hours flexibility, overtime premia are usually increasing in hours. This arises from the increasing difficulty of convincing employees to work overtime above a certain threshold ${ }^{10}$ or, more interestingly from our point of view, from institutional constraints. Given the hourly standard wage $w$, overtime is then regulated in such a way that the first $\left(\bar{h}_{2}-\bar{h}_{1}\right)$ hours exceeding $\bar{h}_{1}$ are paid at a constant rate $w$. Overtime hours that exceed the $\bar{h}_{2}$ level are paid at an increasing rate, with $\phi_{u} g\left(h-\bar{h}_{2}\right)$ being the overtime premium, and $g$ being an increasing convex

\footnotetext{
7"Machines" in Nickell's original terminology.

${ }^{8}$ This assumption can be easily relaxed with no consequences on the predictions of the model if we (reasonably) assume that the employees cannot partecipate to more than one shift per day.

${ }^{9}$ Although this generality enable us to say more about the effects of working time regulations on the cyclical employment dynamics, what we observe in practice in OECD countries is that until recently working time flexibility has been mostly implemented through overtime legislation (See for example Bosch et al., 1993). However, the models's predictions are not affected if we rule out downward working time regulations.

${ }^{10}$ See Santamaki (1983), (1984).
} 
function of hours, i.e. $g^{\prime}>0$ and $g^{\prime \prime}>0$. The parameter $\phi_{u}$ measures overtime legislation. If legislation is strict, the parameter will approach 1 and the firm will pay the maximum amount of overtime premium. If, otherwise, this parameter approaches 0 each overtime hour will just be paid the standard hourly wage. Any value of this parameter in the $\{0,1\}$ interval represents an intermediate degree of overtime flexibility.

For what concerns downward hours flexibility, we assume that the wage schedule for an hours level lower than $\bar{h}_{1}$ is equal to $w \bar{h}_{1}+\phi_{d} w\left(h-\bar{h}_{1}\right)$, where the parameter $\phi_{d}$ measures hours flexibility. The case of $\phi_{d}=0$, with a constant fall back pay equal to $w \bar{h}_{1}$, represents the maximum degree of downward rigidity. In this case the employee is paid as if he worked the standard amount of hours even if the actual working time level is lower. On the contrary, if $\phi_{d}=1$, the firm faces a maximum degree of internal downward flexibility, and it pays only $h \leq \bar{h}_{1}$ effective hours. Any value of this parameter in the $\{0,1\}$ interval represents an intermediate degree of downward flexibility.

In analytical terms, the wage schedule specification is the following:

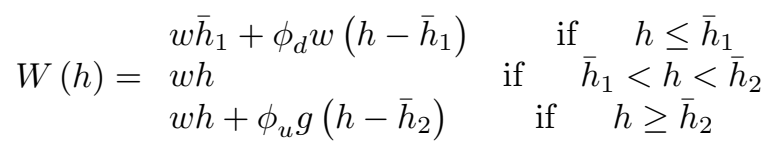

with $\phi_{d}, \phi_{u} \in[0,1]$.

In this model labour input dynamics are characterized by two alternative sources of adjustment: the external and the internal labour market. In other words, the firm can adjust the stock of employees as well as the utilization rate of the existing workforce ${ }^{11}$. The adjustment pattern followed by the firm will be influenced by the labour market institutions that govern external and internal flexibility. External flexibility is affected by dismissals and accessions costs, namely the parameters $a$ and $d$ in the model while internal flexibility is affected by the shape of the wage schedule through the parameters $\phi_{d}$ and $\phi_{u}$.

\subsection{The Dynamics of the System}

The model generates a dynamic path for employment and hours that can be split into different phases, as depicted in Figure 1. Next remarks illustrate the conditions determining the optimal level of $\bar{M}$ and $M$, respectively the minimum and maximum level of employment over the cycle.

Remark 1 The minimum level of employment over the cycle $\bar{M}$, is determined by the equation:

$$
-\left(a e^{-r t_{3}}+d e^{-r t_{2}}\right)=\int_{t_{2}}^{\tilde{t}_{2}} w \bar{h}_{1}\left(\phi_{d}-1\right) e^{-r t} d t
$$

together with the conditions:

$$
\bar{M}=\frac{x\left(t_{2}\right)}{\bar{h}_{1}}=\frac{x\left(t_{3}\right)}{\bar{h}_{2}},
$$

where $t_{2}$ and $t_{3}$ are the time instants marking respectively the start and the end of the slump, and $\tilde{t}_{2}$, with $t_{2}<\tilde{t}_{2}<t_{3}$, is the time instant during the slump in which hours are equal to the standard level $\bar{h}_{1}$.

\footnotetext{
${ }^{11}$ All workers are therefore assumed to be subject to the same working time level, and effort intensity is not taken into account.
} 


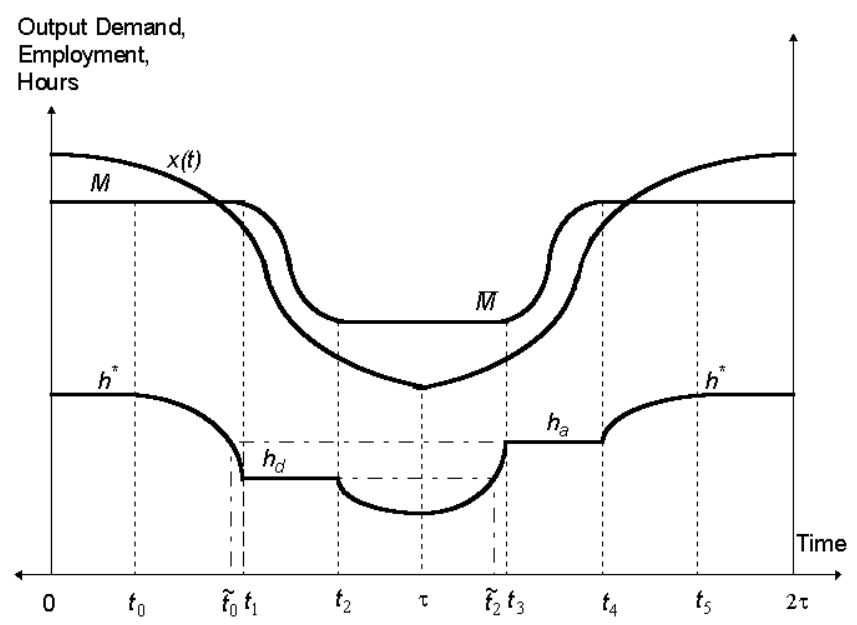

Figure 1: The Dynamics of the System

Proof. See the appendix.

Remark 2 The maximum level of employment over the cycle $M$ is determined by the equation:

$$
\begin{gathered}
\int_{0}^{t_{0}} \phi_{u} \Psi\left(h^{*}\right) e^{-r t} d t+\int_{t_{0}}^{\tilde{t}_{0}} \phi_{u} \Psi(h) e^{-r t} d t+\int_{t_{4}}^{t_{5}} \phi_{u} \Psi(h) e^{-r t} d t+ \\
+\int_{t_{5}}^{2 \tau} \phi_{u} \Psi\left(h^{*}\right) e^{-r t} d t=q \int_{0}^{2 \tau} e^{-r t} d t+a e^{-r t_{4}}+d e^{-r t_{1}}
\end{gathered}
$$

where $t_{0}$ is the time instant when the level of hours starts to decrease from the cyclical peak, $t_{1}$ is the time instant when hours reach the standard level, $\tilde{t}_{0}$, with $t_{0}<\tilde{t}_{0}<t_{1}$, is the time instant when hours equal the $\bar{h}_{2}$ level, $q$ is the retail price of capital, and $\Psi(h)=\left[g^{\prime}\left(h-\bar{h}_{2}\right) h-g\left(h-\bar{h}_{2}\right)\right]$.

Proof. See the appendix.

Using Remarks 1 and 2 we can now assess the predicted impact of labour market institutions on the employment dynamics over the cycle.

\subsection{The Effects of Labour Market Institutions on Cyclical Em- ployment}

The most important implication of the model is that labour market institutions do significantly affect the shape of cyclical employment dynamics. The following remarks illustrate the direction of the impact of these institutions on the employment level in different cyclical phases. Given the objective of this paper, we concentrate on employment protection and working time regulations, represented by the values of parameters $d$ for employment protection, $\phi_{u}$ for overtime standards legislation and $\phi_{d}$ for downward working time flexibility ${ }^{12}$.

\footnotetext{
${ }^{12}$ A similar comparative dynamics exercise can be easily performed on the employment effects of lower accession costs, induced, for example, by active labour market policies. The qualitative results
} 
Remark 3 Stricter employment protection legislation increases the minimum level of employment over the cycle while reducing the level of employment at the peak of the cycle.

Proof. See the appendix.

In other words, tougher employment protection legislation succeeds in increasing the minimum level of employment over the cycle, but the perverse effect of employment protection is that firms reduce the level of employment at the peak of the cycle. Combining these results we see that the variance of employment over the cycle is reduced while we cannot say anything about its average level without making further assumptions ${ }^{13}$.

Turning to working time regulations the next remarks illustrate the effects of upward and downward flexibility on employment levels.

Remark 4 Stricter upward working time regulations (overtime standards) induces an increase in the maximum level of employment over the cycle, leaving employment during the slump unaffected.

Proof. See the appendix.

Remark 5 Stricter downward working time regulations during the slump induce a decrease in the minimum employment level over the cycle, leaving the peak employment level unaffected.

Proof. See the appendix.

Summarising the results contained in the last two remarks we see that the effects of looser working time flexibility (through an increase in the overtime standards parameter $\phi_{u}$ and a decrease in downward flexibility $\phi_{d}$ ) is the opposite of the one induced by looser employment protection regulations. Indeed, looser working time regulations reduce the variance of employment along the cycle while increasing the variance of hours. On the other hand, looser employment protection regulations have the opposite effect of increasing the variance of employment and reducing the variance of hours.

\subsection{The Potential Impact of Downward Working Time Flexi- bility}

On a theoretical level there seems to be no reason for working time to be regulated in the same fashion during slumps and during booms. Slumps are characterized by average levels of actual hours that are lower than the standard amount. Booms are instead characterized by positive levels of overtime. The more flexible are hours during slumps, the lower will be their average level during that particular phase of the cycle. The more flexible are hours during booms, the higher will be the average amount of cyclical overtime. These two kinds of working time flexibility are theoretically distinct, and have distinct effects on the employment dynamics over the cycle.

In a cyclical perspective, like employment protection legislation, downward working time regulations are typically enforced during slumps, i.e. during that particular

are analogous to the ones obtained for employment protection. However, we still lack of a reliable empirical measure of this institutional dimension, and the theory cannot be trivially tested in this case.

${ }^{13}$ This is a standard result in the literature. See Bentolila and Bertola (1990). 
phase of the cycle characterized by a reduction in labour input requirements. However, differently from employment protection and due to the flow nature of hours, higher working time flexibility is going to increase the minimum level of employment over the cycle during slumps, without affecting the maximum level during booms. The result is that the average level of employment along the cycle is also increased.

This result could suggest downward working time flexibility as an appealing policy measure in order to (partially) offset the employment costs of cyclical downturns, especially considering that firms' costs are also reduced. Having said this, downward working time flexibility is not a common practice among OECD countries while overtime regulations are ${ }^{14}$. According to our model, this implies a lower average employment level and higher costs for firms during slumps. This is due to the inability of firms to intervene on the intensive margin during slumps through a reduction of actual working hours. In addition, when temporary layoffs are not a common practice, the amount of actual worked hours is reduced under the standard level through labour hoarding.

The introduction of downward working time flexibility during slumps reduces firms' labour costs and increases the average employment level along the cycle. However, the financial burden of this policy weights on the employed workers. They should accept a lower weekly wage in exchange of higher job security during slumps.

For what concerns overtime standards, stricter regulations produce higher average employment levels during booms. However, firms' costs are also affected, because of the higher marginal overtime premium ${ }^{15}$. In this case, the financial burden of the policy is carried by the firms ${ }^{16}$, even if partly offset by the reduction in the excess demand period ${ }^{17}$.

\section{Empirical analysis}

\subsection{The Employment Responsiveness To Cyclical Dynamics}

Starting from the framework depicted above, our aim is trying to understand how relevant are the implications of the theory at an empirical level. The objective is to test the significance and the direction of the impact of employment protection and working time regulations on the employment responsiveness to cyclical output in 20 OECD countries observed every quarter over the period 1975 - 1997.

Our empirical methodology is first to adopt an unambiguous notion of cycle, second to identify a measure of the employment responsiveness to cyclical dynamics and third to estimate how the latter is affected by a set of institutional indicators.

The first issue is approached by applying the Hodrick - Prescott ${ }^{18}$ filter to output

\footnotetext{
${ }^{14}$ See for example the discussion in Bosch et al. (1993), Buttler et al. (1995) and Bettio et al. (1997).

${ }^{15}$ Besides, if employment is higher during booms, firms are ceteribus paribus going to spend more in hiring and firing costs over the whole cyclical period.

${ }^{16}$ The rent percieved by the employee during booms is also affected. We have two opposite effects: the first, positive, is measured by the increase in the overtime premium, the second, negative, is measured by the lower amount of overtime hours worked by the employee. The net effect on the total overtime salary percieved by each employee is therefore ambiguous.

${ }^{17}$ Note that this result depends on the assumption of production equal to demand in each phase of the cycle. If we introduce the possibility of producing less than the cyclical demand, an increase in overtime costs could affect the firm's optimal production plan, possibly reducing the output and the employment level during the peak of the cycle (see Hart, 1987, for a similar discussion).

${ }^{18}$ See Hodrick and Prescott [1997]. Although the choice of this filtering technique is not exempt from criticism (see King and Rebelo, 1993, and Harvey and Jaeger, 1993) we prefer to follow the
} 
data, identifying the cyclical turning points for each country. As regards the measure of employment responsiveness to cyclical dynamics, this is calculated as the output elasticity of employment over each phase of the cycle. In a detrended world as the one depicted in section 2, the elasticity is simply:

$$
\varepsilon_{M_{1} x}=\frac{\gamma_{M_{1}}}{\gamma_{x}}=\frac{x}{M_{1}} \frac{d M_{1}}{d x}
$$

However, since the actual GDP series are indeed trended, we need to make a distinction between how we calculate $\varepsilon_{M_{1} x}$ in expansions and contractions. In the case of expansions, the trend and the cyclical components of output and employment have the same positive sign. This implies that the elasticity calculated substituting the actual series of output and employment in (9) will be positive and meaningful. Conversely, in the case of contractions, if we calculate the elasticity using actual data, the cyclical and the trend component would cancel out since they have opposite signs. As a result, the information contained in the dependent variable $\varepsilon_{M_{1} x}$ would be totally misleading ${ }^{19}$.

This limitation can be overcome by using filtered data for both output and employment when calculating $\varepsilon_{M_{1} x}$ for contractions. The elasticity will be distorted by the filter anyway, but in a milder way with respect to the case described above. As a result of this, care must be taken in the interpretation of the contraction phase analysis and in the comparison with the expansion phase analysis.

In what follows we present some empirical evidence for different cyclical phases, starting with the expansion phase, following with different segments of the expansion phase, and finally ending with the contraction phase.

\subsection{Expansion Phase Analysis}

\subsubsection{The Predictions of the Theory}

The implications of the theoretical model of section 2 in terms of the effects of labour market institutions on the output elasticity of employment during expansions are summarized by the two following remarks.

Remark 6 Stricter employment protection reduces the output elasticity of employment during the expansion phase.

Proof. See the appendix.

In other words, the employment growth induced during an expansion phase is reduced by stricter employment protection. The firm anticipates the higher costs of dismissals during the contraction phase and reduces the level of accessions during the expansion.

Remark 7 Stricter working time regulations increase the output elasticity of employment over the expansion phase. This is true independently of the form that working time rigidity takes (stricter overtime standards, stricter downward rigidity, or both).

Proof. See the appendix.

In other words, stricter working time regulations, i.e. more internal rigidity, push the firm to vary its labour input requirements on the extensive margin during expansions, increasing the employment growth rate.

standard practice adopted in the business cycle literature.

${ }^{19}$ For example we could end up with a positive output growth rate during a contraction if the positive trend component is larger than the negative cyclical component. 


\begin{tabular}{||c|c|c|c|c|c|c|c|c|c||}
\hline \hline \multicolumn{1}{||c|}{ Expansion Phase 1 } & \multicolumn{3}{|c|}{ Expansion Phase 2 } & \multicolumn{3}{|c|}{ Expansion Phase 3 } \\
\hline Country & start & end & du & start & end & du & start & end & du \\
\hline \hline Austria & $1978-3$ & $1980-2$ & 7 & $1987-3$ & $1991-3$ & 16 & $1993-2$ & $1994-4$ & 6 \\
Belgium & $1979-1$ & $1980-3$ & 6 & $1987-2$ & $1990-3$ & 13 & & & \\
Denmark & $1978-1$ & $1979-3$ & 6 & $1983-2$ & $1986-1$ & 11 & $1993-1$ & $1995-2$ & 9 \\
Finland & $1978-3$ & $1980-2$ & 7 & $1986-3$ & $1989-4$ & 13 & $1993-1$ & $1996-1$ & 12 \\
France & $1977-3$ & $1979-3$ & 8 & $1987-2$ & $1989-4$ & 10 & $1993-3$ & $1995-1$ & 6 \\
Germany & $1977-2$ & $1979-4$ & 10 & & & & $1989-2$ & $1991-3$ & 9 \\
Ireland & $1976-3$ & $1978-2$ & 7 & & & & $1988-2$ & $1990-3$ & 9 \\
Italy & $1978-1$ & $1980-1$ & 8 & $1986-3$ & $1990-1$ & 14 & & & \\
Netherlands & $1978-3$ & $1979-4$ & 5 & $1988-2$ & $1990-2$ & 8 & $1993-3$ & $1994-4$ & 5 \\
Norway & $1978-3$ & $1980-1$ & 6 & $1982-3$ & $1987-1$ & 18 & $1993-1$ & $1994-3$ & 6 \\
Portugal & $1975-3$ & $1977-2$ & 7 & $1978-3$ & $1980-3$ & 8 & $1984-3$ & $1991-3$ & 28 \\
Spain & & & & & & & $1986-2$ & $1990-3$ & 17 \\
Sweden & $1978-1$ & $1980-1$ & 8 & $1982-4$ & $1985-1$ & 9 & $1986-4$ & $1990-2$ & 14 \\
Switzerland & $1978-2$ & $1981-1$ & 11 & $1987-3$ & $1990-2$ & 11 & $1993-3$ & $1995-1$ & 6 \\
United Kingdom & $1975-4$ & $1979-3$ & 15 & $1985-1$ & $1989-1$ & 16 & $1992-3$ & $1995-1$ & 10 \\
Australia & $1977-4$ & $1979-2$ & 6 & $1986-4$ & $1989-4$ & 12 & $1991-4$ & $1994-3$ & 11 \\
Canada & $1977-2$ & $1979-3$ & 9 & $1986-4$ & $1989-3$ & 11 & $1992-3$ & $1995-1$ & 10 \\
Japan & $1977-2$ & $1979-3$ & 9 & $1983-3$ & $1985-2$ & 9 & $1987-1$ & $1991-3$ & 18 \\
New Zealand & $1975-3$ & $1976-4$ & 5 & & & & $1992-3$ & $1994-4$ & 9 \\
United States & $1975-2$ & $1978-4$ & 14 & $1987-1$ & $1989-4$ & 11 & $1991-3$ & $1995-1$ & 14 \\
\hline \hline
\end{tabular}

Table 1: Timing and duration of the expansion phases

\subsubsection{The Econometric Model}

We construct a simple test of the implications of the theoretical model by regressing the output elasticity of employment on a set of institutional indicators and controls. The timing and duration of the Hodrick - Prescott expansion phases identified for each country in the sample are presented in Table 1 while the corresponding elasticity values $^{20}$ are presented in Table 2 . Table 3 shows instead some summary statistics related to the institutional indicators utilized in the analysis. These variables, provided by the OECD and other researchers ${ }^{21}$, describe the strictness of the employment protection and working time regulations in each country, together with other aspects of labour market institutions that are potentially relevant to our analysis. They distinguish between employment protection defined in a broad sense and regulations that specifically target permanent and temporary employment. In addition, they contain information on working time regulations based on a number of different aspects ${ }^{22}$. The theory indicates employment protection and working time standards as the most relevant institutional regressors in shaping employment dynamics over the cycle. However, we test the significance of union coverage and unemployment benefits as well,

\footnotetext{
${ }^{20}$ They are calculated as follows:

$$
\varepsilon_{M_{1} x}^{i t}=\frac{\left\{\frac{M_{1}\left(t_{\text {start }}\right)-M_{1}\left(t_{\text {end }}\right)}{M_{1}\left(t_{\text {start }}\right)}\right\}}{\left\{\frac{x\left(t_{\text {start }}\right)-x\left(t_{\text {end }}\right)}{x\left(t_{\text {start }}\right)}\right\}} \quad \text { for } i=1, \ldots, 20 \quad t=1, \ldots, 3 .
$$

where $M_{1}$ is actual employment and $x$ is actual output, each observed for the $i$-th country, at the start and at the end of the $t$-th phase.

${ }^{21}$ See the appendix for data definitions and sources.

${ }^{22}$ These are: type of regulation (law or collective agreement), contractual working hours, maximum working hours and pay premium for overtime work. See the appendix for information about the time variation of this indicator for each country.
} 


\begin{tabular}{||c|c|c|c||}
\hline \hline Country & Expansion Phase 1 & Expansion Phase 2 & Expansion Phase 3 \\
\hline \hline Austria & 0.054 & 0.394 & 0.474 \\
Belgium & 0.014 & 0.356 & \\
Denmark & 0.297 & 0.512 & 0.074 \\
Finland & 0.495 & 0.137 & 0.049 \\
France & 0.106 & 0.293 & 0.191 \\
Germany & 0.378 & & 0.400 \\
Ireland & 0.263 & & 0.277 \\
Italy & 0.169 & 0.138 & 0.125 \\
Netherlands & 0.374 & 0.526 & 0.328 \\
Norway & 0.165 & 0.373 & 0.368 \\
Portugal & 0.140 & 0.384 & 0.656 \\
Spain & 0.394 & 0.065 & 0.532 \\
Sweden & 0.747 & 0.883 & 0.243 \\
Switzerland & 0.222 & 0.478 & 0.153 \\
United Kingdom & 0.165 & 0.940 & 0.348 \\
Australia & 0.876 & 0.654 & 0.569 \\
Canada & 0.236 & 0.150 & 0.360 \\
Japan & 0.564 & & 0.676 \\
New Zealand & 0.705 & 0.617 & 0.611 \\
United States & 0.335 & 0.431 & 0.334 \\
Mean & 0.237 & 0.247 & 0.202 \\
\hline Standard Deviation & & &
\end{tabular}

Table 2: Output elasticity of employment over the expansion phase

in order to control for the effects of institutions governing labour supply ${ }^{23}$.

A general version of the model is the following:

$$
\begin{array}{r}
\varepsilon_{M_{1} x}^{i t}=\alpha+\beta_{1} E P_{i t}+\beta_{2} W T_{i t}+\beta_{3} U C_{i t}+\beta_{4} L D_{i t}+\beta_{5} B R R_{i t}+\beta_{6} D U_{i t}+\beta_{7} S L_{i t}+\mu_{i}+v_{i t} \\
i=1, \ldots, 20 \quad t=1, \ldots, T_{i} \quad(10)
\end{array}
$$

where:

$\varepsilon_{M_{1} x}^{i t}$ measures the employment responsiveness to the expansion phase;

$\alpha$ is the mean intercept;

$E P_{i t}$ is the employment protection indicator $(d)$;

$W T_{i t}$ is the working time standards indicator $\left(\phi_{u}\right.$ and $\left.\phi_{d}\right)$;

$U C_{i t}$ is the union coverage indicator;

$D U_{i t}$ is the duration of the expansion phase, in quarters;

$S L_{i t}$ is the depth of the slump preceding the expansion;

$\boldsymbol{\beta}$ is the vector of parameters of interest;

$\mu_{i}$ is the time invariant individual specific random effect for the $i$-th country;

$v_{i t}$ is the disturbance term for the $i t$-th observation;

$T_{i}$ is the number of time observations on $i$.

The composite structure of the stochastic term takes into account that subsequent observations from a single country cannot be treated independently. We tested this specification with the usual Hausman test ${ }^{24}$, especially considering the potential correlation between the regressors and the country specific effects. However the random

\footnotetext{
${ }^{23}$ Although this possibility is not included in the theoretical model it is reasonable to assume that unions and benefits may affect the cyclical behaviour of employment in some direction.

${ }^{24}$ See Hausman (1978).
} 


\begin{tabular}{ccccccccccc}
\hline \hline & \multicolumn{2}{c}{$\mathrm{EP}_{i t}$} & \multicolumn{2}{c}{$\mathrm{WT}_{i t}$} & \multicolumn{2}{c}{$\mathrm{EPP}_{i t}$} & \multicolumn{2}{c}{$\mathrm{EPT}_{i t}$} & $\mathrm{EP}_{i}$ & $\mathrm{WT}_{i}$ \\
country & mean & sd & mean & sd & mean & sd & mean & sd & mean & mean \\
\hline \hline Austria & 12.13 & 1.50 & 8.33 & 2.89 & 11.50 & 0.00 & 9.14 & 0.00 & 16.00 & 10.00 \\
Belgium & 15.28 & 0.32 & 0.00 & 0.00 & 6.68 & 0.00 & 17.52 & 0.00 & 17.00 & 0.00 \\
Denmark & 9.95 & 1.82 & 5.00 & 5.00 & 6.90 & 0.09 & 10.78 & 3.66 & 5.00 & 0.00 \\
Finland & 11.65 & 0.61 & 8.33 & 2.89 & 11.24 & 0.94 & 8.56 & 0.00 & 10.00 & 10.00 \\
France & 13.67 & 0.95 & 10.00 & 0.00 & 10.86 & 0.20 & 12.34 & 1.47 & 14.00 & 10.00 \\
Germany & 16.05 & 0.64 & 10.00 & 0.00 & 13.13 & 0.23 & 13.23 & 5.13 & 15.00 & 10.00 \\
Ireland & 5.05 & 0.07 & 17.50 & 3.54 & 7.37 & 0.00 & 1.21 & 0.00 & 12.00 & 20.00 \\
Italy & 19.90 & 0.14 & 12.50 & 3.54 & 11.69 & 0.00 & 20.00 & 0.00 & 20.00 & 10.00 \\
Netherlands & 13.10 & 0.46 & 11.67 & 2.89 & 14.30 & 0.23 & 10.93 & 3.73 & 9.00 & 10.00 \\
Norway & 15.10 & 0.69 & 6.67 & 2.89 & 12.13 & 0.00 & 12.66 & 0.76 & 11.00 & 10.00 \\
Portugal & 18.03 & 1.62 & 10.00 & 0.00 & 19.12 & 1.53 & 12.73 & 0.51 & 18.00 & 10.00 \\
Spain & 18.65 & & 20.00 & & 11.62 & & 13.72 & & 19.00 & 20.00 \\
Sweden & 17.80 & 0.35 & 10.00 & 0.00 & 13.71 & 0.19 & 11.83 & 4.77 & 6.00 & 10.00 \\
Switzerland & 5.50 & 0.00 & 10.00 & 0.00 & 5.21 & 0.00 & 6.55 & 0.00 & 6.00 & 10.00 \\
United Kingdom & 3.50 & 0.00 & 0.00 & 0.00 & 2.98 & 0.00 & 1.21 & 0.00 & 7.00 & 0.00 \\
Australia & 5.00 & 0.00 & 3.33 & 2.89 & 3.14 & 0.00 & 6.55 & 0.00 & 4.00 & 0.00 \\
Canada & 3.00 & 0.00 & 10.00 & 0.00 & 3.34 & 0.00 & 1.21 & 0.00 & 3.00 & 10.00 \\
Japan & 14.00 & 0.00 & 0.00 & 0.00 & 11.39 & 1.10 & 10.64 & 0.98 & 8.00 & 0.00 \\
New Zealand & 8.00 & 0.00 & 0.00 & 0.00 & 5.90 & 0.11 & 2.28 & 0.00 & 2.00 & 0.00 \\
United States & 1.00 & 0.00 & 3.33 & 2.89 & 0.36 & 0.00 & 1.21 & 0.00 & 1.00 & 0.00 \\
Sample Total & 10.90 & 5.69 & 7.36 & 5.24 & 9.05 & 4.88 & 8.89 & 5.45 & 9.53 & 6.98 \\
\hline \hline
\end{tabular}

$\mathrm{EP}_{i t}$ : Employment Protection Indicator $\{1,20\}$ from Blanchard and Wolfers (2000);

$\mathrm{WT}_{i t}$ : Working Time Regulations Indicator $\{0,20\}$ constructed by author using Bosch et al. (1993), OECD Employment Outlook (1994) and EIRO (1998);

$\mathrm{EPP}_{i t}$ : Permanent Employment Protection Indicator $\{1,20\}$ from Nicoletti et al. (2001);

$\mathrm{EPT}_{i t}$ : Temporary Employment Protection Indicator $\{1,20\}$ from Nicoletti et al. (2001);

$\mathrm{EP}_{i}$ : Employment Protection Indicator $\{1,20\}$ from OECD Jobs Study (1994);

$\mathrm{WT}_{i}$ : Working Time Regulations Indicator $\{0,20\}$ from OECD Employment Outlook (1994).

See Data Appendix: Definitions and Sources.

Table 3: Employment Protection and Working Time Regulations Indicators over the expansion phase 
effects specification has not been rejected for any estimated model, as shown in the output tables. The two controls $D U_{i t}$ and $S L_{i t}{ }^{25}$ describe the main characteristics of each expansion phase. It is reasonable to assume that hirings will be affected by the macroeconomic conditions embodied in these two variables.

\subsubsection{The Estimation Results for the Expansion Phase}

The Maximum Likelihood random effects estimates are presented in Table 4. Model 4.A is the benchmark specification that includes time varying institutions and a control for the duration in quarters of the expansion phase. The sensitivity of the estimates to the estimation methods is checked in Table 5 where we confront GLS random effects, MLE random effects and OLS ${ }^{26}$, obtaining a set of coefficients and standard errors of a comprable magnitude.

Our results are consistent with the conclusions of the theory, indicating a positive significant effect of employment protection and a negative significant effect of working time standards. In other words, stricter employment protection regulations and looser working time arrangements are correlated with lower employment growth during expansions.

The duration of the expansion phase has a significant positive impact on the dependent variable. If we are ready to assume that economic agents have a reasonable forecasting power of the expansion duration, this could imply that a longer expansion phase pushes the accession rate up since the utilization of labour is expected to be spread over a more extended period of time.

Models 4.B and 4.C are a modification of the benchmark specification where we introduce a time varying union coverage indicator and a control for the characteristics of the slump preceding the expansion phase. The union coverage variable is significant with negative sign, indicating that stronger unions reduce the rise in employment during expansions ${ }^{27}$. The negative coefficient is expected since we presume that unions' strength is increasing the costs of dismissals, reducing the rate of accessions during the expansion phase. The slump control is however not significant.

In order to check the robustness of these results, the same models are estimated using alternative, although time invariant, institutional indicators produced by the $\mathrm{OECD}^{28}$ in columns 4.D, 4.E and 4.F of the same table. The sign and significance of the institutional effects are confirmed, with the only significant difference of a larger negative coefficient for employment protection when the indicator is time invariant ${ }^{29}$.

\footnotetext{
${ }^{25}$ This variable is calculated as the ratio of the absolute value of the Hodrick-Prescott cyclical component at the start of each phase $t$ over the standard deviation of the cyclical component for the $i$-th country, i.e.

$$
S L_{i t}=\frac{\mid c_{i t}(\text { phase start }) \mid}{S D\left(c_{t}\right)_{i}} .
$$

${ }^{26}$ Note that both random effects GLS and MLE are consistent and should yield the same results for large samples.

${ }^{27}$ This result is not essentially in contradiction with what found by Nickell and Nunziata (2000) in their non linear labour demand equation. There, the authors find that union coverage has a positive effect on the adjustment speed of employment. This is due to the specification of the impact of unions, which includes a negative effect of union density and a positive effect of the interaction of union density with employment protection. Despite the limitations due to the small dimension of our sample, if we introduce union density and an interaction term union density-employment protection in the model, there are signs of a positive effect of the latter (although weak, since the P-value is $0.13)$.

${ }^{28}$ See the appendix for details.

${ }^{29}$ In principle, we could assess the effect of institutional changes by comparing the coefficients of time varying and time invariant indicators. However, the time varying and the time invariant
} 


\begin{tabular}{|c|c|c|c|c|c|c|c|c|c|}
\hline \multirow{3}{*}{$\begin{array}{l}\text { Dep } \\
\text { Employment } \\
\text { Protection }\end{array}$} & $\begin{array}{c}\text { dent Va } \\
\text { 4.A } \\
\text { Time v }\end{array}$ & $\begin{array}{c}\text { iable: } \\
4 . \mathrm{B} \\
\text { rying ins }\end{array}$ & $\begin{array}{c}\text { atput } \mathbf{E} \\
\text { tutions } \\
\end{array}$ & $\begin{array}{c}\text { asticity } \\
4 . D \\
\text { Time in }\end{array}$ & $\begin{array}{l}\text { f Emplc } \\
\mathbf{4 . E} \\
\text { ariant in }\end{array}$ & $\begin{array}{c}\text { ment } \\
4 . \mathbf{F} \\
\text { itutions }\end{array}$ & \multicolumn{3}{|c|}{$\begin{array}{ccc}\text { 4.G } & \text { 4.H } & \text { 4.I } \\
\text { Time varying institutions }\end{array}$} \\
\hline & -0.021 & -0.014 & -0.015 & -0.027 & -0.023 & -0.026 & & & \\
\hline & {$[3.70]$} & {$[2.45]$} & {$[2.71]$} & {$[5.09]$} & {$[3.61]$} & {$[4.07]$} & & & \\
\hline Employment & & & & & & & -0.025 & & -0.020 \\
\hline Protection & & & & & & & {$[3.68]$} & & {$[1.99]$} \\
\hline $\begin{array}{l}\text { Temporary } \\
\text { Employment }\end{array}$ & & & & & & & & -0.017 & -0.007 \\
\hline Protection & & & & & & & & {$[2.85]$} & {$[0.91]$} \\
\hline Working Time & 0.012 & 0.013 & 0.012 & 0.011 & 0.012 & 0.010 & 0.014 & 0.009 & 0.014 \\
\hline & {$[2.00]$} & {$[2.46]$} & {$[2.22]$} & {$[2.15]$} & {$[2.29]$} & {$[2.04]$} & {$[2.35]$} & {$[1.54]$} & {$[2.18]$} \\
\hline Duration of & 0.018 & 0.015 & 0.013 & 0.018 & 0.016 & 0.014 & 0.016 & 0.016 & 0.016 \\
\hline & {$[2.92]$} & {$[2.34]$} & {$[2.02]$} & {$[3.07]$} & [2.69] & {$[2.24]$} & {$[2.63]$} & {$[2.46]$} & {$[2.64]$} \\
\hline Union & & -0.313 & -0.299 & & -0.185 & -0.131 & & & \\
\hline & & {$[2.18]$} & {$[2.16]$} & & {$[1.27]$} & {$[0.91]$} & & & \\
\hline $\begin{array}{l}\text { Depth of } \\
\text { Preceding Slump }\end{array}$ & & & -0.000 & & & -0.001 & & & \\
\hline Constant & $\begin{array}{l}\mathbf{0 . 3 1 8} \\
{[3.35]}\end{array}$ & $\begin{array}{l}\mathbf{0 . 4 8 4} \\
{[4.20]}\end{array}$ & $\begin{array}{l}{[0.79]} \\
\mathbf{0 . 5 0 5} \\
{[4.54]}\end{array}$ & $\begin{array}{l}\mathbf{0 . 3 5 6} \\
{[4.54]}\end{array}$ & $\begin{array}{l}\mathbf{0 . 4 5 7} \\
{[4.12]}\end{array}$ & $\begin{array}{l}{[1.81]} \\
\mathbf{0 . 4 6 9} \\
{[4.35]}\end{array}$ & $\begin{array}{l}\mathbf{0 . 3 2 2} \\
{[3.40]}\end{array}$ & $\begin{array}{l}\mathbf{0 . 2 8 9} \\
{[2.83]}\end{array}$ & $\begin{array}{l}\mathbf{0 . 3 3 1} \\
{[3.18]}\end{array}$ \\
\hline $\begin{array}{l}\text { P-value GQ } \\
\text { Het. Test }\end{array}$ & 0.65 & 0.67 & 0.79 & 0.45 & 0.45 & 0.57 & 0.79 & 0.65 & 0.80 \\
\hline $\begin{array}{l}\text { P-value } \\
\text { Hausman Test }\end{array}$ & 0.38 & 0.56 & 0.05 & 0.93 & 0.71 & 0.23 & 0.19 & 0.12 & 0.24 \\
\hline $\begin{array}{l}\text { P-value Skew. } \\
\text { Norm. Test }\end{array}$ & 0.37 & 0.39 & 0.38 & 0.34 & 0.33 & 0.30 & 0.35 & 0.50 & 0.25 \\
\hline $\begin{array}{l}\text { P-value Sh.-Wi. } \\
\text { Norm. Test }\end{array}$ & 0.93 & 0.97 & 0.94 & 0.80 & 0.84 & 0.78 & 0.90 & 0.87 & 0.23 \\
\hline $\begin{array}{l}\text { MLE random effect } \\
\text { z statistics in brack } \\
\text { Blanchard and Wol } \\
\text { OECD Employmen } \\
\text { total employment } \\
\text { Employment Outloc } \\
\text { employment protect } \\
\text { the working time re } \\
\text { following range: EP }\end{array}$ & $\begin{array}{l}\text { stimates. } \\
\text { Models } \\
\text { (2001), } \\
\text { utlook (1 } \\
\text { ection fro } \\
(1994) . \quad \\
\text {, of temp } \\
\text { lations in } \\
\text {. }\end{array}$ & $\begin{array}{l}\text { nbalance } \\
\text { C use ti } \\
\text { d workin } \\
\text { 4) and } \mathrm{F} \\
\text { OECD } \\
\text { dels G, } \mathrm{H} \\
\text { cary emp } \\
\text { cator is t }\end{array}$ & $\begin{array}{l}\text { Panel: } \\
\text { e varying } \\
\text { time regg } \\
20 \text { (1998 } \\
\text { bs Study } \\
\text { and I use } \\
\text { yment pr } \\
\text { same as }\end{array}$ & $\begin{array}{l}\text { (1994) ar } \\
\text { respectiv } \\
\text { tection, } \\
\text { models A }\end{array}$ & $\begin{array}{l}1, \text { Tma } \\
\text { f total e } \\
\text { tructed } \\
\text { E and } \\
\text { working } \\
\text { a time } \\
\text { both, f } \\
\text { The re }\end{array}$ & $\begin{array}{l}\text { 3, num } \\
\text { loymen } \\
\text { authors } \\
\text { ise time } \\
\text { ne regu } \\
\text { rying ir } \\
\text { n Nicol } \\
\text { ssors ta }\end{array}$ & $\begin{array}{l}\text { of obse } \\
\text { otectior } \\
\text { ing Bos } \\
\text { rariant } \\
\text { ons fron } \\
\text { ator of } \\
\text { et al. } \\
\text { the valu }\end{array}$ & $\begin{array}{l}\text { is=53. } \\
\text { li. (1993) } \\
\text { ors of } \\
\text { D } \\
\text { nent } \\
\text { while } \\
\text { he }\end{array}$ & \\
\hline
\end{tabular}

Table 4: Regressions explaining output elasticity of employment over the expansion phase 


\begin{tabular}{lcrrr}
\hline \hline & \multicolumn{4}{c}{ Model 4.A } \\
& & MLE & GLS & OLS \\
\hline \hline EP & $\hat{\boldsymbol{\beta}}$ & $\mathbf{- 0 . 0 2 1}$ & $\mathbf{- 0 . 0 2 0}$ & $\mathbf{- 0 . 0 2 1}$ \\
& s.e. $(\hat{\boldsymbol{\beta}})$ & 0.006 & 0.006 & 0.005 \\
WT & $\hat{\boldsymbol{\beta}}$ & $\mathbf{0 . 0 1 2}$ & $\mathbf{0 . 0 1 3}$ & $\mathbf{0 . 0 1 1}$ \\
& s.e. $(\hat{\boldsymbol{\beta}})$ & 0.006 & 0.006 & 0.006 \\
DE & $\hat{\boldsymbol{\beta}}$ & $\mathbf{0 . 0 1 8}$ & $\mathbf{0 . 0 1 9}$ & $\mathbf{0 . 0 1 7}$ \\
& s.e. $(\hat{\boldsymbol{\beta}})$ & 0.006 & 0.006 & 0.007 \\
\hline \hline
\end{tabular}

GLS: Balestra-Nerlove random effects estimate;

MLE: max likelihood random effects estimate;

OLS: ordinary least squares estimate.

Table 5: A comparison of different estimation methods for the baseline expansion model

A further step is to check the effects of the employment protection indicators that refer, respectively, to permanent and temporary employment. The evidence suggests that the employment responsiveness to cyclical dynamics is mainly shaped by permanent employment protection ${ }^{30}$. Both indicators are significant, with expected sign, in models 4.G and 4.H. However, the significant effect of temporary employment protection disappears when we control for permanent employment protection in 4.I.

The Hausman test statistics reported in Table 4 supports the random effect specification for each version of the model. A simple Goldfeld-Quandt ${ }^{31}$ test does not reject the hypothesis that the residuals are homoskedastic while their normality is not rejected after both a skeweness and a Shapiro-Wilk test ${ }^{32}$.

\subsubsection{Simulations}

The implications of the models estimated in Table 4 can be summarized by means of a set of simple simulations where the institutional indicators are set to different degrees of flexibility. We simulate the total employment protection model 4.A and the permanent employment protection model 4.G in the case of an expansion phase of average duration.

The output elasticity of employment measures the employment responsiveness to output growth during an expansion phase. We can see from Table $6^{33}$ that the simulated values vary in a range between -0.02 and 0.77 . Some characteristic values

employment protection indicators are not strictly comparable since the latter is a country ranking index.

${ }^{30}$ This is possibly due to the fact that OECD employment is mainly permament and therefore responds principally on regulations that concern this type of employees. See OECD (1999) and Nunziata and Staffolani (2001) for a broader discussion on permanent and temporary employment regulations.

${ }^{31}$ The version of the test presented in the table ranks the residuals according to their magnitude. Similar results were found adopting different ranking criteria. See Goldfeld and Quandt (1965).

${ }^{32}$ See D'Agostino et al. (1990) and Shapiro and Wilk (1965).

${ }^{33}$ The values corresponding to very high, high, average, low, very low employment protection are respectively: 20, $15,10,5,1$, considering that the average value of Employment Protection for the 20 OECD countries in the sample is around 10. The Working Time Standards variable is instead respectively equal to $20,7.4$ and 0 in the case of strict, average or loose regulations, since the sample mean is around 7.4 . 


\begin{tabular}{cccc}
\hline \hline & & \multicolumn{2}{c}{$\begin{array}{c}\text { Simulated Output } \\
\text { Elasticity of Employment }\end{array}$} \\
Employment Protection & Working Time Standards & EP Simulation $(4 . \mathrm{A})^{a}$ & ${\text { EPP Simulation }(4 . G)^{b}}^{b}$ \\
\hline \hline Very High & Loose & 0.09 & -0.02 \\
Very High & Average & 0.17 & 0.09 \\
Very High & Strict & 0.32 & 0.26 \\
High & Loose & 0.19 & 0.11 \\
High & Average & 0.28 & 0.21 \\
High & Strict & 0.42 & 0.39 \\
Average & Loose & 0.29 & 0.23 \\
Average & Average & 0.38 & 0.34 \\
Average & Strict & 0.53 & 0.51 \\
Low & Loose & 0.40 & 0.36 \\
Low & Average & 0.48 & 0.46 \\
Low & Strict & 0.63 & 0.64 \\
Very Low & Loose & 0.50 & 0.48 \\
Very Low & Average & 0.59 & 0.59 \\
Very Low & Strict & 0.73 & 0.77 \\
\hline \hline
\end{tabular}

\footnotetext{
${ }^{a}$ Predicted Output Elasticity of Employment, baseline model 4.A including Total

Employment Protection.

${ }^{b}$ Predicted Output Elasticity of Employment, baseline model 4.G including Permanent

Employment Protection.
}

Table 6: Model 1 simulations for an average duration expansive phase (10 quarters)

are reported in Figure 2 for a visual comparison.

Very high employment protection together with loose working time standards can cause employment not to vary at all during expansions. The greater labour input requirements are satisfied by means of higher actual working hours because of the greater costs of discounted dismissals. On the contrary, very low employment protection accompanied by strict working time standards yields an elasticity value equal to about three quarters. Hence, for example, an output growth rate of 2 percentage points over one expansion year is accompanied by an employment growth rate of one and an half percentage points.

The most flexible situation with very low employment protection and loose overtime standards is characterized by an elasticity value of around 0.5 , such that about one half of the output growth is translated into employment growth. This is the same result yielded by very different labour market institutional configurations such as the one characterized by an average employment protection and strict working time standards or low employment protection and average working time standards. For what concerns the most rigid market, the predicted output elasticity of employment is equal to 0.32 when we control for total employment regulations, and to 0.26 when we control for permanent employment regulations.

The average labour market configuration, with average levels of both institutions, yields an elasticity level equal, respectively, to 0.38 and 0.34 in the two alternative models. This values are not far from the outcome of the flexible and the rigid market, characterized respectively by low and high levels of both variables. This is because the effect of the flexibility on the external margin is compensated by the flexibility on the internal margin. The former induces a larger employment increase, the latter triggers a larger variation in hours, reducing the one in employment.

In general, the total employment protection model yields larger elasticity values 


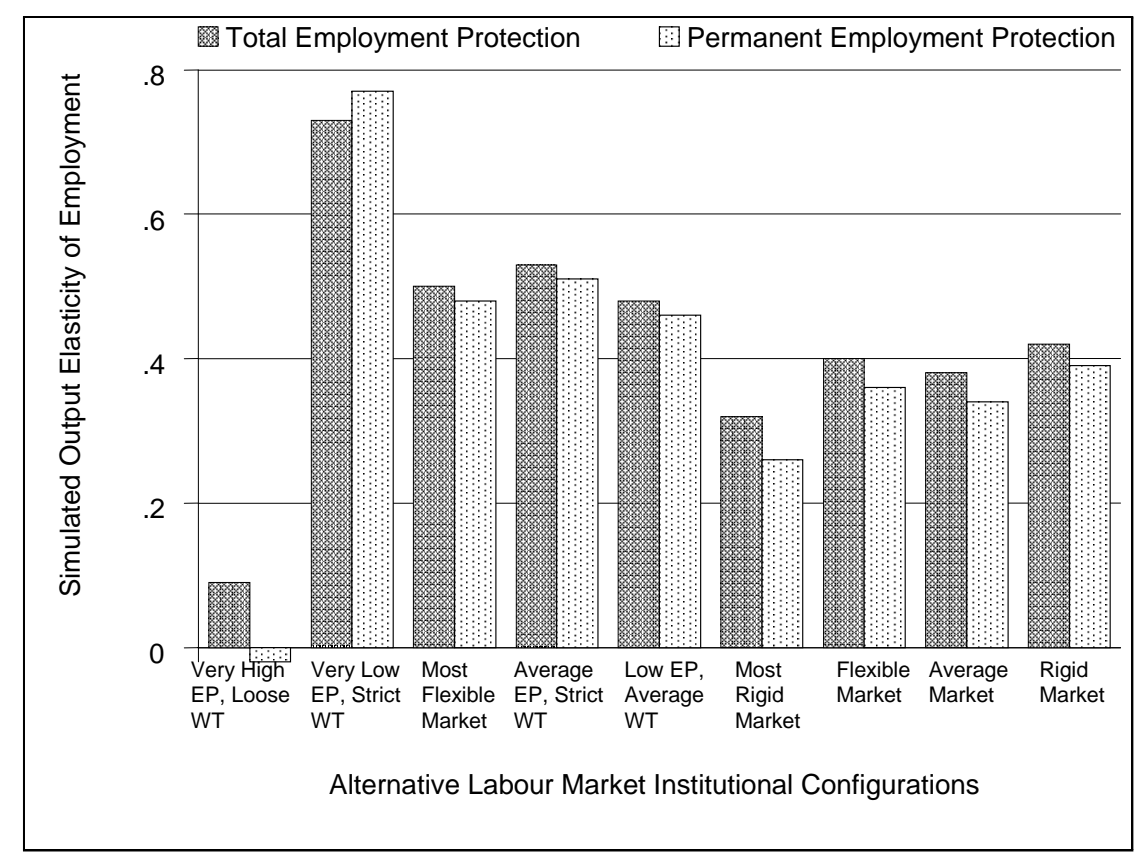

Figure 2: Selected simulated values for output elasticity of employment over the expansive phase

than the permanent employment protection $\operatorname{model}^{34}$.

As a summary of the results above, the empirical analysis confirms the validity of the theoretical argument explaining the employment dynamics over the cycle. For what concerns the expansion phase, employment protection and working time regulations have both a significant impact on employment growth rates. In addition, the same employment cyclical pattern can be generated by very dissimilar institutional configurations of the labour market.

\subsection{Expansion Phase Segments Analysis}

\subsubsection{The Model}

Our aim in this section is to check, respectively, if the employment growth rate is constant along the expansion phase and if the impact of the institutions is symmetric along different segments of the phase. We attempt to answer to these questions looking at the same expansion phase panel analysed in section 3.2 , but calculating the elasticity variable for each half of each expansion. The estimation procedure is the same as the previous section, with the only difference that we introduce a dummy variable $\varphi_{i t}$ that takes the value 1 if the elasticity is calculated for the first half of the expansion and 0 if it is calculated for the second half, i.e.

$$
\begin{array}{ll}
\varphi_{i t}=1 & \text { if } i \in\{\text { first segment }\} \\
\varphi_{i t}=0 & \text { if } i \in\{\text { second segment }\} .
\end{array}
$$

\footnotetext{
${ }^{34} \mathrm{An}$ exception is the case of maximum predicted elasticity.
} 
We then interact the dummy variable with the institutional indicators in order to test for asymmetric institutional effects. The model we estimate is therefore the following:

$\varepsilon_{M_{1} x}^{i t}=\alpha+\beta_{1} E P_{i t}+\beta_{2} W T_{i t}+\beta_{3} U C_{i t}+\beta_{4} \varphi_{i t}+\beta_{5}\left(\varphi_{i t} E P_{i t}\right)+\beta_{6}\left(\varphi_{i t} W T_{i t}\right)+\mu_{i}+v_{i t}$

where the coefficients $\alpha, \beta_{1}, \beta_{2}$ and $\beta_{3}$ are the same of equation (10), measuring, respectively, the mean intercept and the coefficients of employment protection, working time regulations and union coverage; the coefficient $\beta_{4}$ measures the mean intercept effect of the first segment dummy; and the parameters $\beta_{5}$ and $\beta_{6}$ indicate its slope effects on employment protection and working time regulations, respectively.

\subsubsection{The Estimation Results for the Expansion's Segments}

The pooled regressions are presented in Table 7, where we see that the "first half" dummy is highly significant with negative sign in all specifications. In practice, the output elasticity of employment varies over the cycle, with lower values in correspondence to the beginning of each expansion and higher values towards the end. In other words, there seems to be a systematic tendency for employment to grow more over the last segment of the expansion phase.

The sign and significance of institutions are respected apart from the case of union coverage whose effect is weaker. The hypothesis of an asymmetric impact of institutions along the expansion is not rejected for employment protection only. In this case the interaction is significant with positive sign, indicating that the marginal effect of employment protection over the first half of the expansion phase is sensibly reduced. The size of the reduction depends on the specification of the model. Model 7.B, that includes a total employment protection indicator, shows an almost zero impact of employment protection in the first half and a coefficient for the second half that is much larger than the one estimated in Table 4. However, Model 7.G, that includes a permanent employment protection indicator, points out a coefficient equal to -0.014 for the first half and -0.038 for the second. The general indication is that employment protection does matter more in the segment of the expansion phase characterized by faster employment growth, i.e. the second half.

There are a number of possible explanations for this. One argument lies simply in the fact that employment needs time to adjust, maybe because of the delay in the agents' recognition of the turning point, or just because the hiring process takes time. According to this view, employment growth is slow in the first part of the expansion phase, whatever the institutional configuration of the labour market. In the second part of the phase employment starts growing faster, at a speed determined by the flexibility of employment protection regulations. On the other hand, the impact of working time regulations on hours, and therefore on employment, is the same in different segments of the expansion.

Looking at more structural explanations, Caballero and Hammour (1994) and Nickell, Nicolitsas and Patterson (1997) identify what is known in the literature as the cleansing effect of contractions. In other words, the threat of bankruptcy could induce firms to reorganize the production process during contractions, with a subsequent increase in the productivity level. As the expansion phase begins, this is reflected in a slower increase in accessions, especially during the first half. 


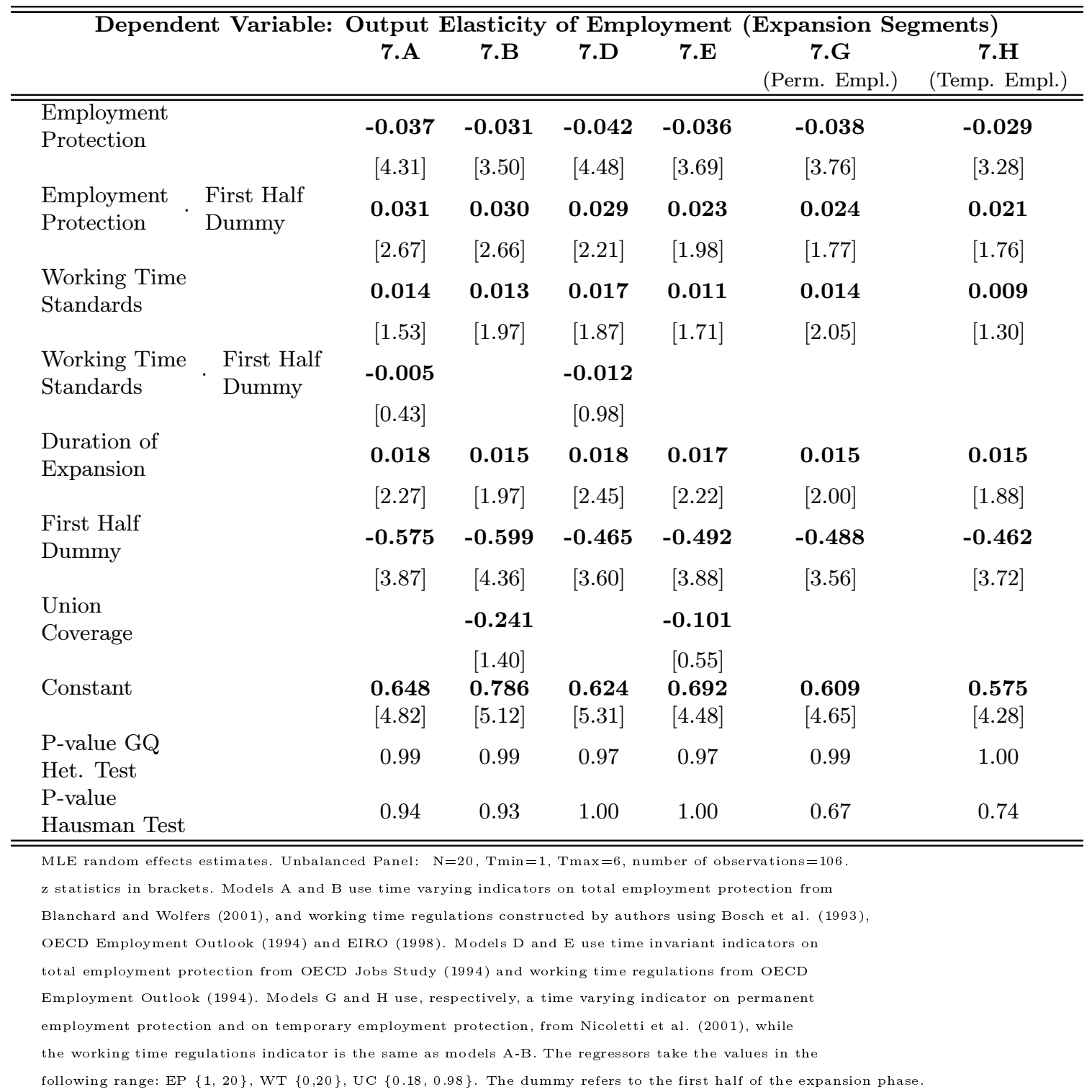

Table 7: Regression explaining output elasticity of employment over the expansion segments 


\subsection{Contraction Phase Analysis}

\subsubsection{The Predictions of the Theory}

Following the same logic adopted for expansions the implications of the theoretical model for the contraction phase can be summarized in the next two remarks.

Remark 8 Stricter employment protection reduces the output elasticity of employment during the contraction phase.

Proof. See the appendix.

Remark 9 Stricter working time regulations increase the output elasticity of employment over the contraction phase. This is true independently of the form that working time rigidity takes (stricter overtime standards, stricter downward rigidity, or both).

Proof. See the appendix.

The indication of Remark 8 is by definition what one would expect from employment protection legislation. On the other hand, Remark 9 indicates that stricter working time rigidity induces a larger employment reduction during contractions since the decreasing labour input requirements cannot be accommodated by means of a large variation in hours.

\subsubsection{The Estimation Results for the Contraction Phase}

We report three simple models calculated for contractions, following a procedure similar to the one adopted for expansions. We first identify the major contractions occurred in each country from 1975 to 1997 using the HP filter. We then calculate the output elasticity of employment over each contraction. In doing this, differently from what we do with expansions, we use filtered data in order to eliminate the problem of having a trend and a cyclical component of opposite sign. Unfortunately, the filter distorts the information contained in the series, as discussed above. The estimates of Table 8, reported for sake of completeness, suffer therefore the limitation of not being strictly comparable with the ones of the previous tables. The effects of employment protection and working time regulations are nevertheless significant and with expected sign while the random effects specification and homoskedasticity are not rejected. Perhaps a suspicious sign of distortion is the lack of significance of the duration control.

\subsection{Some Notes on the Cyclical Behaviour of Hours}

In addition to the analysis of cyclical employment presented so far, an interesting issue that remains to be investigated is the cyclical behaviour of hours. This is not an easy task given the serious limitations of the data on worked hours in OECD countries. When available, the quarterly series of hours are also not very informative. The series actual hours for employees from BSDB, for example, although measuring the actual and not the standard level, do not show any cyclical pattern for some of the countries in the sample. It is the case of France, as we can see in Fig. 3, where the actual hours series seem to reflect the decennial downward trend in standard hours, more than any cyclical variation. However, looking at figures 4 and 5 we notice that in the cases of United States and Canada, the dynamics of actual hours is as expected. 


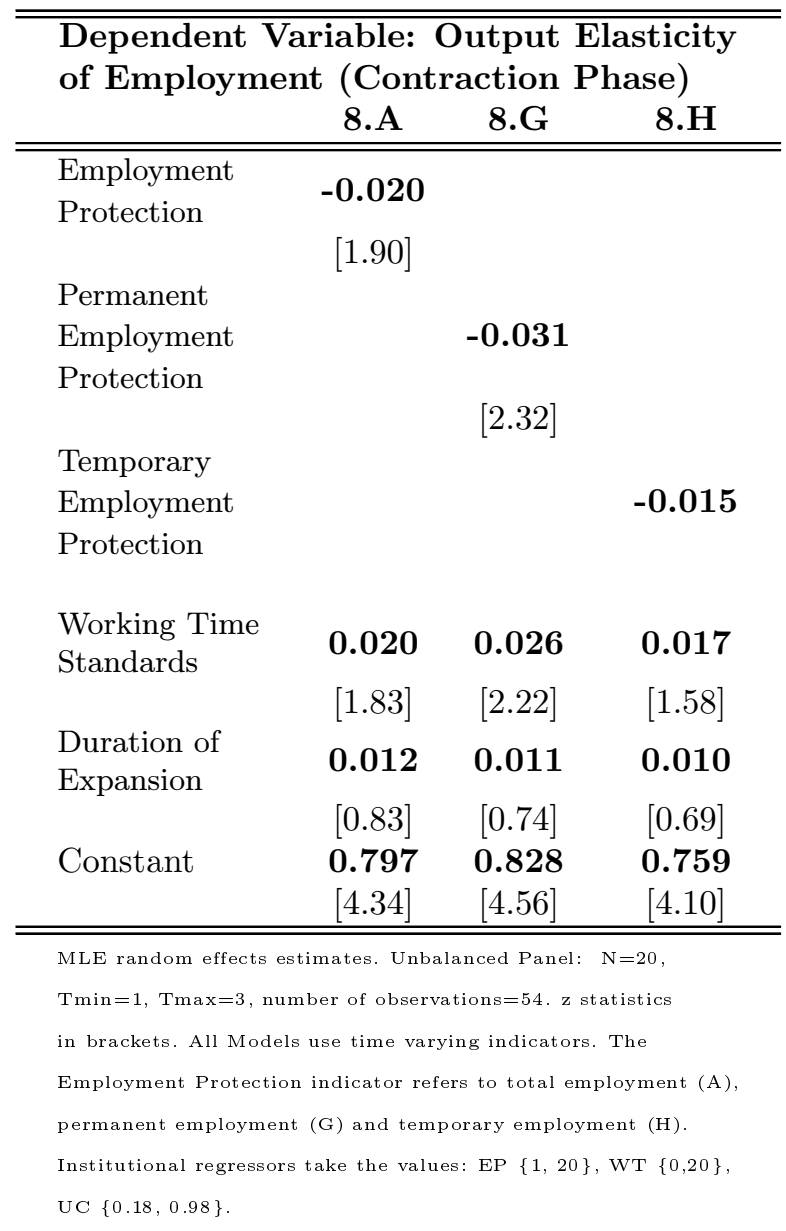

Table 8: Regression explaining output elasticity of employment over the contraction phase 


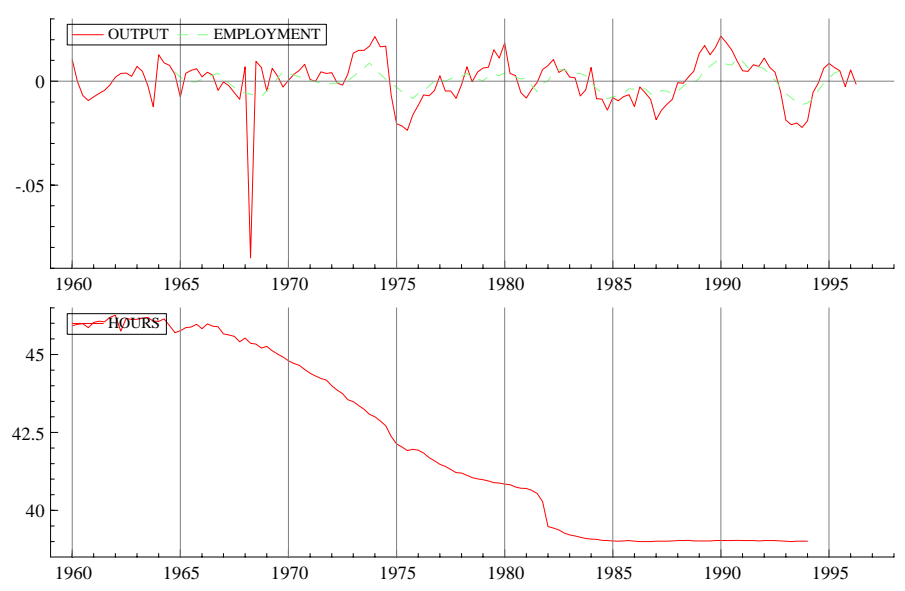

Figure 3: Cyclical behaviour of Output and Employment, and level of Actual Hours for France (1960-1997)

In countries with loose employment protection regulations the increase in hours is especially concentrated in the first half of the phase and the variance is limited ${ }^{35}$.

\subsection{Institutions Affecting Labour Supply}

Finally, it is worthwhile to spend some words on the impact of institutions affecting labour supply. The competition among firms in attracting new workers is higher during the peak of the cycle, in presence of lower unemployment. However, at a theoretical level, the firms' hiring margins could be reduced further by higher unemployment benefits since the reservation wage of unemployed individuals would be increased. As a consequence of this, we should expect a significant negative effect of unemployment benefits on the output elasticity of employment. Still, this effect is not confirmed by the analysis, and the amount and duration of benefits are never significant in models estimated over different phases. A possible interpretation of this is that, on average, firms are not labour supply constrained during booms.

\section{Concluding Remarks}

We present an empirical analysis of the effects of labour market institutions on the employment responsiveness to the business cyle, focusing on the role played by employment protection regulations and working time standards. The analysis is introduced by a theoretical model based on Nickell (1978) where we consider the impact

\footnotetext{
${ }^{35}$ The quarterly BSBD provides data on only a few of the 20 OECD countries in the sample. However it is possible to run a very simple regression with exploratory purposes. In fact one could construct the output elasticity of actual hours using quarterly as well as yearly data from $O E C D$ Main Economic Indicators Series, remembering that we only need data on the turning points or on some approximation of those. A simple regression for 18 OECD countries (consisting of all countries in the sample except Belgium and New Zealand for which no data are available) of the output elasticity of hours $\varepsilon_{h x}$ on the usual institutional regressors and controls does not show more than a negative correlation with working time standards together and a positive correlation with Union Coverage.
} 

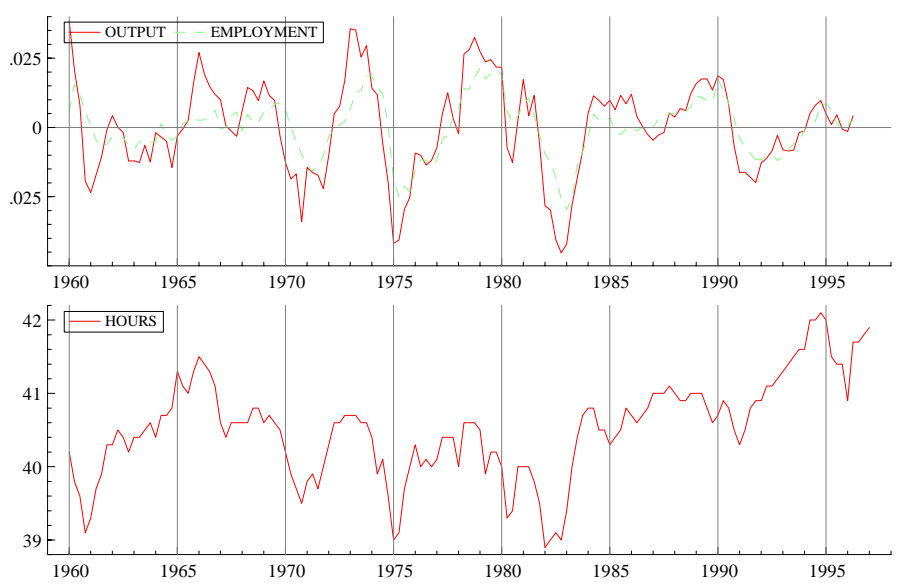

Figure 4: Cyclical behaviour of Output and level of Actual Hours for United States (19601997)
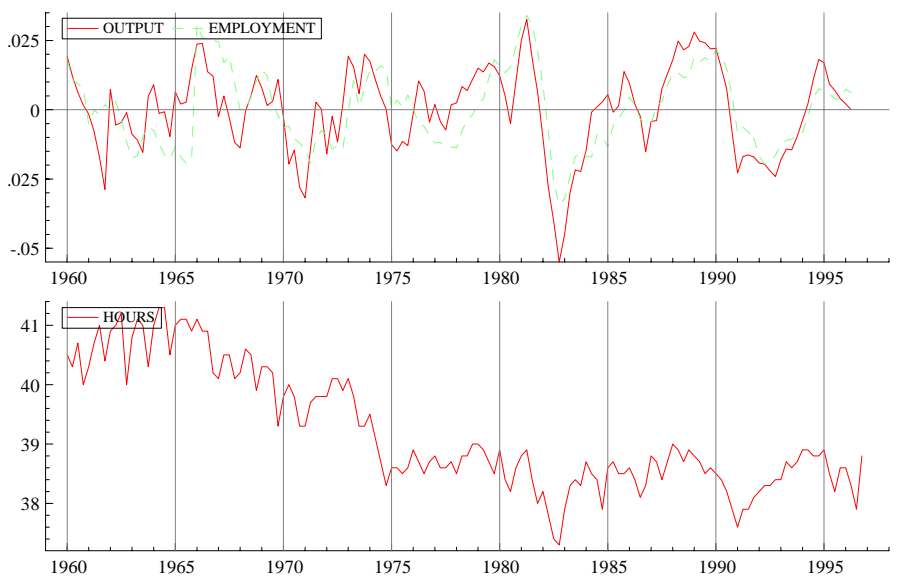

Figure 5: Cyclical behaviour of Output and Employment and level of Actual hours for Canada (1960-1997) 
of institutions on the cyclical dynamics of employment and hours. In particular we analyse the effects of overtime standards as well as the potential role of downward working time regulations during the slump. The predictions of the model are tested on a sample of 20 OECD countries observed for the period 1975-1995.

Our results are as follows:

1. At the theoretical level, labour market institutions have a significant impact on the employment dynamics along the cycle. Stricter employment protection regulations reduce dismissals during contractions, at the same time reducing accessions during expansions ${ }^{36}$. Working time standards have a similar impact, with stricter regulations increasing the employment reactivity to the cycle.

2. A potential policy implication of the model is that the introduction of downward working time flexibility during slumps can induce an increase in the average employment level over the cycle.

3. The theoretical argument is confirmed at an empirical level. The employment responsiveness to cyclical output is significantly affected by employment protection and working time regulations. The evidence suggests also that cyclical employment is mainly affected by permanent employment regulations.

4. The duration of the cyclical phase has a significant positive impact on the employment growth rate during expansions. Union coverage has a significant negative impact, and the effect of unemployment benefits is negligible in all phases.

5. The expansion phase model simulations show that similar levels of output elasticity of employment can be generated by very different labour market institutional configurations. More specifically, a flexible and a rigid labour market produce very similar outcomes.

6. The analysis of different segments of the expansion phase shows that the employment growth is concentrated in the second half of the expansion. Moreover, the impact of employment protection regulations is asymmetric along the phase, with a larger effect in the second segment while working time standards have a symmetric impact.

7. Our findings suggest that the cyclical dynamics of employment in OECD countries are shaped by the specific combination of rigidity and flexibility over the intensive and the extensive margin, as well as over the different phases of the cycle.

\footnotetext{
${ }^{36}$ Although these effects seem to balance over the whole cyclical period this does not imply that the effect on the average employment level over the cycle is negligible. With respect to this point, the empirical results of Nickell and Nunziata (2000) show that employment protection has a significant negative impact on overall employment rates, but not on the employment rate of prime aged males. This suggests that the burden falls mainly on young men, old men and women.
} 


\section{References}

[1] Employment Outlook. OECD, Paris, 1999.

[2] M. Belot and J. Van Ours. Does the Recent Success of Some OECD Countries in Lowering their Unemployment Rates Lie in the Clever Design of their Labour Market Reforms? IZA Discussion Paper, (147), 2000.

[3] S. Bentolila and G. Bertola. Firing Costs and Labour Demand: how bad is Eurosclerosis? Review of Economic Studies, 57:381-402, 1990.

[4] G. Bertola. Microeconomic Perspectives on Aggregate Labor Market. EUI working paper ECO, (98/23), 1998.

[5] G. Bertola, F.D. Blau, and L.M. Kahn. Comparative Analysis of Labor Market Outcomes: Lessons for the US from International Long-Run Evidence. in A.Krieger and R.Solow eds., The Roaring Nineties: Can Full Employment Be Sustained?, 2001.

[6] F. Bettio, E. Del Bono, and M. Smith. Employment and Working Time Policies: a Gender Perspective. A Report of the Network of Experts on the Situation of Women in the Labour Market for the Equal Opportunities Unit (DG-V). European Commission, 1997.

[7] O. Blanchard and J. Wolfers. The Role of Shocks and Institutions in the Rise of European Unemployment: the Aggregate Evidence. The Economic Journal, (462), 2000.

[8] G. Bosch, P. Dawkins, and eds F. Michon. Times are changing: Working time in 14 industrialised countries. ILO, Geneva, 1993.

[9] F. Buttler, W. Franz, R. Schettkat, and D. Soskice (1995). Institutional Frameworks and Labor Market Performance. Routledge, 1995.

[10] R. Caballero and M. Hammour 1996. The cleansing effect of recessions. American Economic Review, 84(5), 1996.

[11] Lars Calmfors and Michael Hoel. Work sharing, employment and shiftwork. Oxford Economic Paper, 461:758-773, 1989.

[12] T. Cogley and J. Nason. Effects of the hodrick-prescott filter on trend and difference stationary time series: Implications for business cycle research. Journal of Economics Dynamics and Control, 19, 1995.

[13] R.B. D'Agostino, A. Balanger, and R.B. D'Agostino Jr. A suggestion for using powerful and informative tests of normality. The American Statistician, 44(4):316-321, 1990.

[14] EIRO: European Foundation for the Improvement of Living and Working Conditions. Flexibility of working time in Europe. 1998.

[15] P. Garibaldi and P. Mauro P. Deconstructing job creation. IMF Working Paper, (WP/99/109), 1999.

[16] S. Goldfeld and R. Quandt. Some Tests for Homoscedasticity. Journal of the American Statistical Association, 60:539-547, 1965. 
[17] D. Hamermesh. Labor Demand. Princeton University Press, 1993.

[18] A. Harvey and A. Jaeger. Detrending, stilized facts and the business cycle. Journal of Monetary Economics, 21, 1993.

[19] J.A. Hausman. Specification tests in econometrics. Econometrica, 46:1251-1272, 1978.

[20] R. Hodrick and E. Prescott E. (1997). Postwar u.s. business cycles: an empirical investigation. Journal of Money, Credit and Banking, 1997.

[21] H. Hoon. Economic effects of worksharing in a dynamic labor turnover model. Politica Economica, 1995.

[22] R. King and S. Rebelo. Low frequency filtering and real business cycles. Journal of Economics Dynamics and Control, 17, 1993.

[23] R. Layard, S.J. Nickell, and R. Jackman. Unemployment: macroeconomic performance and the labour market. Oxford University Press, 1991.

[24] E. Lazear. Job Security Provision and Employment. Quarterly Journal of Economics, 1990.

[25] S.J. Nickell. Fixed Costs, Employment and Labour Demand Over the Cycle. Economica, (1):329-345, November 1978.

[26] S.J. Nickell. Dynamic Models of Labour Demand. Ashenfelter and Layard eds, Handbook of Labor Economics, I, 1986.

[27] S.J. Nickell. Unemployment and labor market rigidities: Europe versus North America. Economic Perspecties, (3):55-73, 1997.

[28] S.J. Nickell. Employment Dynamics and Labour Market Institutions. J. Gual ed., Job creation: The role of labor market institutions. Cheltenham, U.K. and Northampton, Mass.: Elgar, pages 34-48, 1998.

[29] S.J. Nickell, D. Nicolitsas, and M. Patterson. Does doing badly encourage management innovation? Oxford Bulletin of Economics and Statistics, 63(1):5-28, February 2001.

[30] S.J. Nickell and L. Nunziata. Employment Patterns in OECD Countries. CEP Discussion Paper, (448), March 2000.

[31] S.J. Nickell and L. Nunziata. Labour Market Institutions Database. CEP, LSE, September 2001.

[32] S.J. Nickell, L. Nunziata, W. Ochel, and G. Quintini. The Beveridge Curve, Unemployment and Wages in the OECD. CEP Discussion Paper (502), July 2001, forthcoming in M. Woodford (ed.) "Knowledge, Information and Expectations in Modern Macroeconomics: Papers in Honor of Edmund S. Phelps", Princeton University Press, 2002.

[33] S.J. Nickell and R. Layard R. Labour Market Institutions and Economic Performance. in Ashenfelter and Layard eds, Handbook of Labor Economics, NorthHolland Press, III, 1999. 
[34] G. Nicoletti, R.C.G. Haffner, S.J. Nickell, S. Scarpetta, and G. Zoega. European Integration, Liberalisation, and Labour-Market Performance. in Bertola G., T. Boeri and G. Nicoletti eds, Welfare and Employment in a United Europe, Cambridge, MIT Press, 2001.

[35] L. Nunziata. The Effects of Labour Market Institutions on The Employment Dynamics over The Cycle. Nuffield College Economics Discussion Paper, (1999W26), September 1999.

[36] L. Nunziata and S. Staffolani. On Short-Term Contracts Regulations. Nuffield College Working Papers in Economics, (2001-W7), 2001.

[37] OECD. Business Sector Database. Paris.

[38] OECD. Employment Outlook. Paris, 1994.

[39] OECD. Jobs Study: Evidence and Explanations. Paris, 1994.

[40] OECD. Employment Outlook. Paris, 1999.

[41] T. Santamaki. The Overtime Pay Premium, Hours of Work and Employment. Helsinki School of Economics Working Paper, (F-75), 1983.

[42] T. Santamaki. Employment and Hours Decision, and the Willingness to Work Overtime Hours. Helsinki School of Economics Working Paper, (F-86), 1984.

[43] S.S. Shapiro and M.B. Wilk. An analysis of variance test for normality (complete samples). Biometrika, 52:591-611, 1965.

[44] S. Staffolani. La flessibilità quantitativa nel rapporto di lavoro: un'analisi teorica. Economia e Lavoro, 4, 1992. 


\section{A Appendix: FOCs and Proof Derivations}

The model's dynamic optimization problem is simply solved augmenting the Hamiltonian into a Lagrangian function, obtaining:

$L=e^{-r t}\left\{p h M_{1}-W(h) M_{1}-a A-d D\right\}+\lambda_{1}(A-D)+\mu_{1}\left(M-M_{1}\right)+\mu_{2}\left(x-h M_{1}\right)$

where $A, D, h$ are the control variables, and $M_{1}$ is the state variable.

The first order conditions are the following:

$$
\begin{gathered}
\frac{\partial L}{\partial A} \equiv-a e^{-r t}+\lambda_{1} \leq 0, \quad A \geq 0, \quad A \frac{\partial L}{\partial A}=0, \\
\frac{\partial L}{\partial D} \equiv-d e^{-r t}-\lambda_{1} \leq 0, \quad \text { if } \quad M_{1}>0, \quad h \geq 0, \quad h \frac{\partial L}{\partial h}=0, \\
\frac{\partial L}{\partial h} \equiv e^{-r t}\left\{p-W^{\prime}(h)\right\}-\mu_{2} \leq 0, \quad D \frac{\partial L}{\partial D}=0, \\
\dot{M}_{1}=\frac{\partial L}{\partial \lambda_{1}} \equiv A-D ; \\
\dot{\lambda}_{1}=-\frac{\partial L}{\partial M_{1}} \equiv-\left\{e^{-r t}[p h-W(h)]-\mu_{1}-h \mu_{2}\right\} ; \\
\frac{\partial L}{\partial \mu_{1}} \equiv M-M_{1} \geq 0, \quad \mu_{1} \geq 0, \quad \mu_{1} \frac{\partial L}{\partial \mu_{1}}=0, \\
\frac{\partial L}{\partial \mu_{2}} \equiv x-h M_{1} \geq 0, \quad \mu_{2} \geq 0, \quad \mu_{2} \frac{\partial L}{\partial \mu_{2}}=0,
\end{gathered}
$$

Substituting $\mu_{2}$ from condition (16) into (18) we end up with

$$
\dot{\lambda}_{1}=\mu_{1}-Z(h) e^{-r t}
$$

Proof of Remark 1. Integrating both sides of the first order condition of problem (1) with respect to $M_{1}$ we obtain $\int_{t_{2}}^{t_{3}} \dot{\lambda}_{1} d t=-\int_{t_{2}}^{t_{3}} Z\{h(t)\} e^{-r t} d t$ where $Z(h)=h W^{\prime}(h)-W(h)$. This equation, together with the first order conditions with respect to $A$ and $D$, give equation (6). The 3 equations system formed by (6) and (7) identifies $\bar{M}, t_{2}$ and $t_{3}$.

Proof of Remark 2. $M$ is set to maximize the present value of firm's profits, calculated as revenues minus wage costs, capital costs and adjustment costs. Considering that $x\left(t_{1}\right)=M h_{1}$ and $x\left(t_{4}\right)=M h_{2}$, the first order condition of the problem is:

$$
\begin{aligned}
& \int_{0}^{t_{0}} W^{\prime}\left(h^{*}\right) h^{*} e^{-r t} d t+\int_{t_{5}}^{2 \tau} W^{\prime}\left(h^{*}\right) h^{*} e^{-r t} d t+ \\
&-\int_{0}^{2 \tau} q e^{-r t} d t-\int_{0}^{t_{0}} W\left(h^{*}\right) e^{-r t} d t+\int_{t_{0}}^{t_{1}} Z(h) e^{-r t} d t+ \\
& \quad+\int_{t_{4}}^{t_{5}} Z(h) e^{-r t} d t-\int_{t_{5}}^{2 \tau} W\left(h^{*}\right) e^{-r t} d t=d e^{-r t}+a e^{-r t} .
\end{aligned}
$$

Rewriting (22) taking into account the definition of $\tilde{t}_{0}$ we obtain (8).

Proof of Remark 3. From (6) we obtain:

$$
\frac{\partial t_{3}}{\partial d}=\frac{e^{-r t_{2}}}{a r e^{-r t_{3}}}>0,
$$


that together with $(7)$ gives

$$
\frac{\partial \bar{M}}{\partial d}=\underbrace{\frac{\dot{x}\left(t_{3}\right)}{\bar{h}_{2}}}_{(+)} \underbrace{\frac{\partial t_{3}}{\partial d}}_{(+)}>0 .
$$

In addition, from equation (22) we have:

$$
\frac{\partial M}{\partial d}=-\frac{M}{\phi_{u}} e^{-r t_{1}}\left\{\int_{t_{0}}^{\tilde{t}_{0}} g^{\prime \prime} h^{2} e^{-r t} d t+\int_{t_{4}}^{t_{5}} g^{\prime \prime} h^{2} e^{-r t} d t\right\}^{-1}<0 .
$$

Proof of Remark 4. From equation (22) we have:

$$
\begin{aligned}
& \frac{\partial M}{\partial \phi_{u}}=\frac{M}{\phi_{u}} . \\
& \cdot \frac{\left\{\int_{0}^{t_{0}} \Psi\left(h^{*}\right) e^{-r t} d t+\int_{t_{0}}^{\tilde{t}_{0}} \Psi(h) e^{-r t} d t+\int_{t_{4}}^{t_{5}} \Psi(h) e^{-r t} d t+\int_{t_{5}}^{2 \tau} \Psi\left(h^{*}\right) e^{-r t} d t\right\}}{\left\{\int_{t_{0}}^{\tilde{t}_{0}} g^{\prime \prime} h^{2} e^{-r t} d t+\int_{t_{4}}^{t_{5}} g^{\prime \prime} h^{2} e^{-r t} d t\right\}}>0
\end{aligned}
$$

where $\Psi(h)=\left[g^{\prime}\left(h-\bar{h}_{2}\right) h-g\left(h-\bar{h}_{2}\right)\right]>0$, since $g^{\prime}>g / h \forall h$, being $g$ convex. Considering (6) and (7) we see that the level of $\bar{M}$ is unaffected by $\phi_{u}$.

Proof of Remark 5. Differentiating equation (6) we obtain:

$$
\frac{\partial t_{3}}{\partial \phi_{d}}=\left\{\int_{t_{2}}^{\tilde{t}_{2}} w \bar{h}_{1} e^{-r t} d t\right\}\left(a r e^{-r t_{3}}\right)^{-1}>0 .
$$

and hence

$$
\frac{\partial \bar{M}}{\partial \phi_{d}}=\underbrace{\frac{\dot{x}\left(t_{3}\right)}{\bar{h}_{2}} \frac{\partial t_{3}}{\partial \phi_{d}}}_{(+)}>0
$$

From equation (22) we see that $M$ is unaffected by $\phi_{d}$. Increasing downward working time flexibility reduces the dismissal rate during contractions, increasing the number of employees who can retain their jobs in that phase of the cycle. Given that $\bar{M}$ is higher, the dismissal period will be shorter, as well as the hiring phase, with an overall increase in the length of period $\left\{t_{2}, t_{3}\right\}$, when $M_{1}=\bar{M}$. This is because the firm does not need to hire as the cycle recovers since the number of employees is already higher than in the alternative case of rigid working time regulations during the slump. The labour input adjustments will be made through the adjustment of hours. Notice that if $\phi_{d}=0$ we are in the case of a constant fall back pay equal to $w \bar{h}_{1}$, with the firm simply hoarding labour as actual hours fall below the standard level.

Proof of Remark 6. The output elasticity of employment over the expansion phase is equal to:

$$
\varepsilon_{M_{1} x}=\frac{\gamma_{M}}{\gamma_{x}}
$$

where $\gamma_{x}$ is the rate of growth of output during the expansion phase, with $\gamma_{x}>0$ by definition, and $\gamma_{M_{1}}$ is the employment rate of growth during the same expansion. Using the notation of section 2 we have:

$$
\gamma_{M_{1}}=\frac{M-\bar{M}}{\bar{M}}
$$


where $M$ is the maximum level of employment over the cycle and $\bar{M}$ is the minimum level. Using the results of Remark 3 we obtain:

$$
\frac{\partial \varepsilon_{M_{1} x}}{\partial E P}=\left\{\frac{1}{\bar{M}} \frac{\partial M}{\partial d}-\frac{M}{\bar{M}_{(-)}^{2}} \frac{\partial \bar{M}}{\partial d}\right\} \gamma_{x}^{-1}<0
$$

where the employment protection variable $E P$ corresponds to the theoretical parameter $d$.

Proof of Remark 7. Using the results of Remarks 2 and 3 we obtain:

$$
\frac{\partial \varepsilon_{M_{1} x}}{\partial W T}=\frac{1}{\gamma_{x}}\left\{\frac{1}{\bar{M}} \frac{\partial M}{\partial \phi_{u}}-\frac{1}{\bar{M}^{2}}\left[-M \frac{\partial \bar{M}}{\partial \phi_{d}}\right]\right\}>0 .
$$

where the Working Time Standards variable indicates the combined effect of the two variables measuring upward and downward flexibility, respectively $\phi_{u}$ and $\phi_{d}$. Hence, stricter working time rigidity measured by higher values of $W T$, corresponds to higher levels of $\phi_{u}$ and lower levels of $\phi_{d}$, i.e. greater costs of increasing the level of working hours during booms and reducing them during slumps.

Proof of Remark 8. The negative rate of growth of employment during the contraction phase is:

$$
\gamma_{M_{1}}=\frac{\bar{M}-M}{M}
$$

where $M$ is the maximum level of employment over the cycle and $\bar{M}$ is the minimum level. We therefore obtain:

$$
\frac{\partial \varepsilon_{M_{1} x}}{\partial E P}=\left\{\frac{1}{M} \frac{\partial \bar{M}}{\partial d}-\frac{\bar{M}}{M_{(+)}^{2}} \frac{\partial M}{\partial d}\right\} \underset{(-)}{\gamma_{x}}<0 .
$$

Proof of Remark 9. Similarly we have:

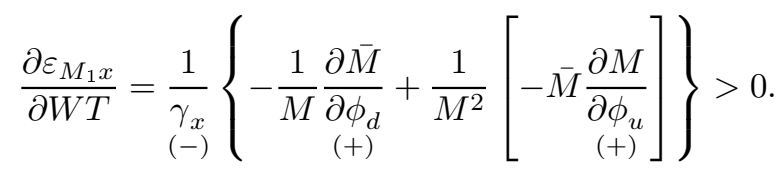




\section{B Appendix: Data, Definitions and Sources}

The output and employment data are taken from OECD Business Sector Database $(B S D B)$, that contains quarterly data for 25 OECD member countries defined for the business sector and the total economy. The series are seasonally adjusted. The countries in the sample are the same as the ones considered in previous analysis ${ }^{37}$ :

$1=$ Austria, $2=$ Belgium, $3=$ Denmark, $4=$ Finland, $5=$ France, $6=$ Germany, $7=$ Ireland, $8=$ Italy, $9=$ Netherlands, $10=$ Norway, $11=$ Portugal, $12=$ Spain, $13=$ Sweden, $14=$ Switzerland, 15=United Kingdom, 16=Australia, 17=Canada, $18=$ Japan, 19=New Zealand, $20=$ United States.

The series are Gross Domestic Product (market prices), Volume for output and Total Employment for employment. Since the BSDB provides aggregate data for West and East Germany after 1991-1, we used data for West Germany from 1991-1 onward taken from Quarterly National Accounts, GDP Volume, seasonally adjusted and $O E C D$ Main Economic Indicators Series, Total Employment, seasonally adjusted by the author.

The characteristics and sources of the variables containing information about the institutional configuration of the labour market are the following.

Employment Protection (time varying): $\mathbf{E P}_{i t}\{1,20\}$

It corresponds to the parameter $d$ of the theoretical model of section two. At the empirical level we distinguish between employment protection for permanent employment, temporary employment and total employment. The indexes describe the strength of the legal framework governing hiring and firing of the different categories of employees. The total employment protection index is provided by Blanchard and Wolfers (2000) . This series was built chaining OECD data with data from Lazear (1990) and is increasing in the strictness of employment protection ${ }^{38}$.

Permanent Employment Protection (time varying): $\mathbf{E P P}_{i t}\{1,20\}$

The permanent employment protection index is provided by the OECD ${ }^{39}$ and is increasing in the strictness of employment protection.

Temporary Employment Protection (time varying): $\mathbf{E P T}_{i t}\{1,20\}$

The temporary employment protection index is also provided by the OECD and is increasing in the strictness of employment protection.

Employment Protection (time invariant): $\mathbf{E P}_{i}\{1,20\}$

The source is OECD Jobs Study (1994), Part II, Table 6.7, column 5. It is a ranking index of total employment protection, ranging from 1 to 20, with 1 indicating the less strictly regulated country.

Working Time Standards (time varying): $\mathbf{W} \mathbf{T}_{i t}\{0,20\}$

The index describes the degree of institutional regulation of working time. It is a time varying version of the time invariant index $\mathbf{W} \mathbf{T}_{i}$ below calculated by the author. The most important changes in working time regulations have been identified for each country and are reported in Table 9 . A score of \pm 5 was assigned to the original time invariant index according to the direction of the change, i.e. if towards greater rigidity or flexibility.

Working Time Standards (time invariant): $\mathbf{W T}_{i}\{0,20\}$

\footnotetext{
${ }^{37}$ See Layard et al. (1991), Nickell (1997), Nickell and Layard (1997), Nickell and Nunziata (2000) and Nickell et al. (2001).

${ }^{38}$ See also Nickell and Nunziata (2001).

${ }^{39}$ See OECD Employment Outlook (1999) for a summary of the data and a description of the methodology used in constructing the indexes. A related discussion can be found in Nicoletti et al (2001).
} 


\begin{tabular}{ll}
\hline \hline & $\begin{array}{l}\text { Changes in Working Time Regulations } \\
(-)=-5 \text { in OECD indicator } \\
(+)=+5 \text { in OECD indicator }\end{array}$ \\
\hline \hline Australia & $1993-95(-)$, enterprise level working time bargaining agreements. \\
Austria & $1983(+)$ Rest Periods Act. \\
Denmark & $1986-1990(++)$ NWW reduced from 40 hours to $37 ;(-)$ the \\
& collective bargaining level shifted to sectoral level; \\
& $1995(-)$ working time flexibility is a key issue in collective bargaining. \\
Finland & $1993(-)$ liberalisation of working time collective agreements; \\
France & $1982(+)$ The Statute; 1986-1987 (-) Delebarre Act and Seguin Act. \\
Ireland & $1987(+)$ Programme for National Recovery \\
Italy & $1984(-)$ More flexible overtime regulations. \\
Japan & $1987(-+)$ Labour Standard Law and NWW reduced to 40 hours. \\
Netherlands & $1986(-)$ Abolition of the prohibition for women night shifts. \\
& Trend towards decentralisation. \\
Norway & $1986(+)$ NWW reduced from 40 hours to 37.5 with a collective \\
& agreement. \\
Portugal & $1982(+)$ maximum of NWW set at 45 hours with a collective \\
& agreement covering a large number of workers; \\
Spain & $1990(-)$ Economic and Social Agreement \\
& $1983(+)$ NWW set at 40 hours; $1994(-)$ regulations made more \\
United States & flexible through annual computation of hours. \\
& $1983(+)$ The Fair Labour Standards extended to state and local \\
& government employees.
\end{tabular}

The reported changes refer to the time period covered by the analysis in the paper.

The information on working time institutional change was provided by EIRO (1998)

and Bosch et al. (1993)

Table 9: Major Changes in Working Time Regulations in OECD Countries 
The index describes the degree of institutional regulation of working time. The source is OECD Employment Outlook (1994), Table 4.8, column 1, extended by Nickell (1997) for Australia, Japan and New Zealand. It ranges from 0 (lax or no legislation) to 20 (strict legislation) and is one of the five dimensions of which it is constituted the labour standards comprehensive variable, column 6 of the same table. The index is constructed using information on type of regulation (law or collective agreement), contractual working hours, maximum working hours and pay premium for overtime work. See also OECD Employment Outlook (1998), Table 5.10.

It plays the role of overall working time standards, therefore comprising both parameters $\phi_{u}$ and $\phi_{d}$ of the theoretical model. We cannot disentangle their individual weight in the construction of the index, but the experience of most OECD countries indicate that these regulations mainly affect overtime standards.

Union Coverage: $\mathbf{U C}_{i t}\{.18, .98\}$

The index indicates the proportion of workers covered by collective bargaining and is constructed using OECD coverage data and time varying density data by Nickell and Nunziata (2001).

Unemployment Benefits Replacement Rates and Duration: $\mathbf{B R R}_{i t}\{0, .87\}, \mathbf{B D}_{i t}$ $\{0,1.04\}$

The indicators measure the amount and duration of unemployment benefits in each country. They are provided by Nickell and Nunziata (2001) and constructed using original OECD unpublished data. 